\title{
Some new sequences that converge to a generalization of Euler's constant
}

\section{ALINA SÎNTĂMĂRIAN}

\section{ABSTRACT.}

The purpose of this paper is to study the properties of some sequences that converge quickly to a generalization of Euler's constant, i.e. the limit of the sequence

$$
\left(\frac{1}{a}+\frac{1}{a+1}+\cdots+\frac{1}{a+n-1}-\ln \frac{a+n-1}{a}\right)_{n \in \mathbb{N}}
$$

where $a \in(0,+\infty)$.

TECHNICAL UNIVERSITY OF CLUJ-NAPOCA

DEPARTMENT OF MATHEMATICS

MEMORANDUMULUI 28

400114 Cluj-NAPOCA, ROMANIA

E-mail address: Alina.Sintamarian@math.utcluj.ro

Received: 03.08.2011; In revised form: 15.09.2011; Accepted: 30.09.2011.

2000 Mathematics Subject Classification. 11Y60, 11B68, 40A05.

Key words and phrases. Sequences, convergence, approximation, Euler's constant, Bernoulli numbers. 